\title{
PENGUKURAN EFEKTIFITAS DAN FREKUENSI FAKTOR YANG MEMPENGARUHI PRODUKTIVITAS PEKERJA PADA PEKERJAAN FINISHING PROYEK RUMAH TINGGAL DI SURABAYA
}

\author{
Anton Prayogo ${ }^{1}$ dan Ratna ${ }^{2}$
}

\begin{abstract}
ABSTRAK: Dalam dunia konstruksi, produktivitas adalah salah satu faktor penentu keberhasilan proyek. Pengukuran tingkat efektifitas tenaga kerja dapat dilakukan dengan menggunakan metode field rating yang mengklasifikasikan aktivitas pekerja dalam kategori bekerja dan tidak bekerja.Besarnya tingkat produktivitas kerja juga dipengaruhi oleh banyak faktor yang terjadi di lapangan, yaitu metode \& teknologi, manajemen lapangan, lingkungan kerja, dan manusia.

Penelitian dilakukan dengan pengamatan dan menyebar kuesioner. Pekerjaan finishing yang diamati yaitu pekerjaan plesteran, keramik dan pengecatan. Hasilnya didapatkan bahwa tingkat keefektifan tukang pada pekerjaan plesteran sebesar $83,86 \%$ dan tingkat keefektifan pembantu tukang sebesar $80,22 \%$, tingkat keefektifan tukang pada pekerjaan keramik sebesar $86,22 \%$ dan tingkat keefektifan pembantu tukang sebesar $78,34 \%$, tingkat keefektifan tukang pada pekerjaan pengecatan sebesar $82,88 \%$ dan tingkat keefektifan pembantu tukang sebesar $79,51 \%$. Sedangkan frekuensi faktor-faktor yang mempengaruhi produktivitas pekerja pada pekerjaan finishing dengan nilai mean paling besar hingga terkecil terdapat dalam faktor (1) manusia, (2) manajemen lapangan, (3) lingkungan kerja, dan (4) metode \& teknologi.
\end{abstract}

Kata kunci: produktivitas, efektifitas, faktor-faktor, pekerjaan finishing.

ABSTRACT: In construction work, productivity is one of the factors that determine the success of a project. To measure the effectivity of labors have many ways, one of them is used field rating. The method simply categorizes the observed worker as either working and non-working. The level of labor productivity also affected by many factors that happening in work area, like method \& technology, field management, working area, and human.

This research is taken by observation and give a questionnaire to labors. Finishing work that observed is plastering, flooring, and painting. The effectivity craftmans result at plastering work amount $83,86 \%$ and the effectivity prentice amount $80,22 \%$; The effectivity craftmans result at flooring work amount $86,22 \%$ and the effectivity prentice amount $78,34 \%$; The effectivity craftmans result at painting work amount $82,88 \%$ and the effectivity prentice amount $79,51 \%$. Whereas the frequency of the factors that affect the productivity of workers on the finishing work with amean value from the highest to the smallest are : (1) human, (2) field management, (3)work environment, and (4) method \& technology.

Keywords: productivity, effectivity, factors, finishing work.

\footnotetext{
${ }^{1}$ Mahasiswa Program Studi Magister Teknik Sipil Universitas Kristen Petra, antonk1990.ap@gmail.com

2Dosen Program Studi Magister Teknik Sipil Universitas Kristen Petra, alifrat@petra.ac.id
} 


\section{PENDAHULUAN}

1.1. Latar Belakang

Pada saat ini banyak proyek rumah tinggal yang mengalami keterlambatan dalam penyelesaiannya terutama di pekerjaan finishing. Pekerjaan finishing adalah pekerjaan yang kompleks sehingga tidak semua pekerja dapat melakukan pekerjaan tersebut. Adapun mereka yang mampu bekerja tetapi pada umumnya meminta upah kerja harian karena proses penyelesaian pekerjaan finishing membutuhkan waktu yang relatif lama. Hal ini tentu meresahkan para kontraktor rumah tinggal apabila hasil yang didapat tidak sebanding denganupah kerja yang dikeluarkan. Produktivitas tenaga kerja yang baik sangat diperlukan karena akan mempengaruhi terhadap besar kecilnya keuntungan ataupun kerugian dalam suatu proyek pembangunan.

Salah satu kendala yang dihadapi kontraktor rumah tinggal adalah mencari tenaga kerja.Sumber daya manusia adalah salah satu faktor yang sangat berpengaruh dalam suatu proyek. Dalam upaya mengatur penggunaan sumber daya manusia, maka kontraktor harus mengetahui tingkat keefektifan masing-masing pekerja. Seringkali dalam pelaksanaan di lapangan terjadi tindakan-tindakan kurang efektif yang dilakukan oleh pekerja seperti : menganggur, merokok, mengobrol, makan diluar jam istirahat, dan lain sebagainya. Selain itu juga masih terdapat faktor-faktor lain di lapangan yang menjadi pengaruh terhadap produktivitas tenaga kerja. Dalam pengukuran produktivitas terdapat banyak metode yang dapat digunakan, salah satunya dengan field rating. Metode ini mengklasifikasikan aktivitas pekerja kedalam 2 kategori, yaitu working (bekerja) dan non-working (tidak bekerja). Pengukuran dan pengolahan data faktor-faktor yang mempengaruhi produktivitas tenaga kerja juga digunakan metode pendekatan dengan analisa deskriptif. Penelitian ini dilakukan pada proyek-proyek rumah tinggal yang sedang berlangsung di kota Surabaya.

\subsection{Rumusan Masalah}

Bagaimana tingkat keefektifan tenaga kerja pada pekerjaan finishing proyek rumah tinggal di Surabaya?

Bagaimana frekuensi faktor-faktor yang mempengaruhi produktivitas pekerja di lapangan pada pekerjaan finishing proyek rumah tinggal di Surabaya?

\subsection{Tujuan Penelitian}

Mengetahui seberapa besar tingkat keefektifan tenaga kerja pada pekerjaan finishing proyek rumah tinggal di Surabaya.

Mengetahui faktor-faktor yang sering terjadi di lapangan pada pekerjaan finishing proyek rumah tinggal di Surabaya.

\subsection{Manfaat Penelitian}

Bagi peneliti dan kontraktor diharapkan dapat bermanfaat untuk lebih memahami faktorfaktor yang mempengaruhi produktivitas pekerja untuk meningkatkan produktivitas proyek serta dapat mengambil langkah maupun keputusan dalam membangun suatu proyek rumah tinggal.

\subsection{Ruang Lingkup Penelitian}

Responden kuesioner adalah mandor, tukang, dan pembantu tukang.

Sistem upah tenaga kerja harian.

Proyek rumah tinggal kelas menengah yang berlokasi di Surabaya.

\section{LANDASAN TEORI}

\subsection{Pendahuluan}

Menurut Soeharto (1995), dalam dunia konstruksi agar mampu bergerak dengan produktif dalam pelaksanaannya dipengaruhi oleh mutu, biaya, dan waktu tertentu sehingga untuk mendapatkan hasil yang diiinginkan sangat diperlukan peran sumber daya manusia yang baik. Oleh karena itu, dalam merencanakan tenaga kerja hendaknya dilengkapi dengan analisis produktivitas dan indikasi variabel yang mempengaruhinya. 


\subsection{Produktivitas dan Efektifitas}

Produktivitas didefinisikan sebagai rasio antara output dengan input, atau rasio antara pengeluaran dan hasil produksi dengan total sumber daya yang digunakan. Dalam proyek konstruksi, rasio produktivitas adalah nilai yang diukur selama proses konstruksi yang dapat dipisahkan menjadi biaya tenaga kerja, material, dan alat. Permasalahan produktivitas juga berkaitan dengan seberapa besar pekerjaan itu digolongkan dalam kelompok kerja yang efektif. Efektif biasanya digunakan sebagai perbandingan dimana sasaran yang diinginkan dapat tercapai. Sedangkan pengertian efektifitas adalah suatu perbandingan antara evaluasi pekerjaan dari satu unit output dengan evaluasi satu unit input. Sukses tidaknya proyek konstruksi bergantung pada efektifitas pengelolaan sumber daya tersebut. Tingkat produktivitas pekerja ini sangat sulit diukur secara akurat dan memerlukan tenaga dan biaya yang sangat besar (Olomolaiye, 1998).

\subsection{Peningkatan Produktivitas}

Peningkatan produktivitas dapat dicapai dengan menekan sekecil-kecilnya segala macam biaya termasuk dalam memanfaatkan tenaga kerja. Dengan kata lain produktivitas merupakan pencerminan dari tingkat efisiensi dan efektifitas kerja secara total. Bila seseorang atau sekelompok orang yang terorganisir melakukan pekerjaan yang berulangulang, maka diharapkan akan terjadi suatu pengurangan jam tenaga kerja atau biaya untuk menyelesaikan pekerjaan selanjutnya. Di area dengan jumlah besar sering terjadi pemborosan tenaga, waktu, dan uang (Oglesby, 1989:171).

\subsubsection{Pengukuran Produktivitas Tenaga Kerja}

Salah satu pendekatan untuk mengukur tingkat keefektifan tenaga kerja adalah menggunakan metode field rating. Cara pengelompokan pengamatan dilakukan dengan mengklasifikasikan aktivitas pekerja kedalam 2 kategori, yaitu working (bekerja) dan nonworking (tidak bekerja). Hasil pengukuran dikatakan memuaskan apabila hasilnya lebih besar dari $60 \%$.

\subsection{Faktor-Faktor yang Mempengaruhi Produktivitas Konstruksi}

Menurut Kaming dalam Ervianto (2004) faktor yang mempengaruhi produktivitas proyek diklasifikasikan menjadi empat kategori utama, yaitu:

1. Metode dan teknologi, terdiri atas faktor desain rekayasa, metode konstruksi, urutan kerja, dan pengukuran kerja.

2. Manajemen lapangan, teridri atas faktor perencanaan dan penjadwalan, tata letak lapangan, komunikasi lapangan, manajemen material, manajemen peralatan, manajemen tenaga kerja.

3. Lingkungan kerja, terdiri atas faktor keselamatan kerja, lingkungan fisik, kualitas pengawasan, keamanan kerja, latihan kerja, partisipasi.

4. Manusia terdiri atas faktor tingkat upah pekerja, kepuasan kerja, pembagian keuntungan, hubungan kerja antara mandor dengan pekerja.

\subsubsection{Faktor di Lapangan yang Mempengaruhi Produktivitas Pekerja}

Terdapat banyak faktor yang mempengaruhi produktivitas dalam dunia konstruksi yang dipengaruhi oleh berbagai macam hal mulai dari kecil hingga besarnya suatu proyek. Dalam beberapa penelitian yang pernah dilakukan sebelumnya terdapat berbagai macam faktor pada proyek konstruksi yang dapat dilihat dalam Tabel 1. 
Tabel 1. Faktor-Faktor Lapangan yang Mempengaruhi Produktivitas Kerja pada Proyek Konstruksi

\begin{tabular}{|c|c|c|c|c|c|c|c|c|c|c|c|c|c|c|}
\hline \multirow{2}{*}{ No. } & \multirow{2}{*}{$\begin{array}{c}\text { Faktor - Faktor yang Mempengaruhi } \\
\text { Produktivitas }\end{array}$} & \multicolumn{13}{|c|}{ Sumber } \\
\hline & & $\mathrm{A}$ & $\mathrm{B}$ & $\mathrm{C}$ & $\mathrm{D}$ & $\mathrm{E}$ & $\mathrm{F}$ & $\mathrm{G}$ & $\mathrm{H}$ & I & $\mathrm{J}$ & $\mathrm{K}$ & $\mathrm{L}$ & $\mathrm{M}$ \\
\hline 1 & Rendahnya motivasi pekerja & & $\sqrt{ }$ & & & $\sqrt{ }$ & & & & & $\sqrt{ }$ & & & \\
\hline 2 & Rendahnya kemampuan pekerja & & $\sqrt{ }$ & & & & & & $\sqrt{ }$ & & $\sqrt{ }$ & & & \\
\hline 3 & Keletihan & & & & & & & & & & & $\sqrt{ }$ & & $\sqrt{ }$ \\
\hline 4 & Kurangnya program instruksi dan mandor & $\sqrt{ }$ & & & $\sqrt{ }$ & & & & & & $\sqrt{ }$ & & & \\
\hline 5 & $\begin{array}{l}\text { Peralatan yang dipakai sudah usang atau sering } \\
\text { rusak }\end{array}$ & & & $\sqrt{ }$ & $\sqrt{ }$ & & & & & $\sqrt{ }$ & $\sqrt{ }$ & & & \\
\hline 6 & Cuaca yang buruk & & & $\sqrt{ }$ & & & & & & & $\sqrt{ }$ & & & \\
\hline 7 & Jam lembur & & & & & & & & & & & $\sqrt{ }$ & & $\sqrt{ }$ \\
\hline 8 & Kurangnya pengakuan atas hasil pekerjaan & & $\sqrt{ }$ & & & $\sqrt{ }$ & & & & & $\sqrt{ }$ & & & \\
\hline 9 & Tidak tersedianya material & & & $\sqrt{ }$ & & & & & & $\sqrt{ }$ & & & & \\
\hline 10 & Tidak tersedianya peralatan & & & $\sqrt{ }$ & $\sqrt{ }$ & & & & & $\sqrt{ }$ & $\sqrt{ }$ & & & \\
\hline 11 & $\begin{array}{l}\text { Tidak tersedianya perlengkapan tukang } \\
\text { (obeng, palu, cangkul, dll) }\end{array}$ & & & $\sqrt{ }$ & $\sqrt{ }$ & & & & & $\sqrt{ }$ & $\checkmark$ & & & \\
\hline 12 & Absen dan pergantian pekerja & & & & & & $\sqrt{ }$ & $\sqrt{ }$ & & & & & & \\
\hline 13 & Datang terlambat, tapi pulang lebih awal & & & & & & $\sqrt{ }$ & $\sqrt{ }$ & & & & & & \\
\hline 14 & Interferensi & $\sqrt{ }$ & & & $\sqrt{ }$ & & & & & & $\sqrt{ }$ & & & \\
\hline 15 & $\begin{array}{l}\text { Kelompok kerja yang tidak seimbang (terlalu } \\
\text { banyak/terlalu sedikit) }\end{array}$ & $\sqrt{ }$ & & & $\sqrt{ }$ & & & & & & $\checkmark$ & & & \\
\hline 16 & Overcrowded & $\sqrt{ }$ & & & $\sqrt{ }$ & & & & & & & & & \\
\hline 17 & Kecelakaan kerja & & & & & & $\sqrt{ }$ & $\sqrt{ }$ & & & & & & \\
\hline 18 & Kondisi kerja yang tidak aman & & & & & & & & & & & & & \\
\hline 19 & Pemogokan/Penghentian proyek & & & & & & $\sqrt{ }$ & $\sqrt{ }$ & & & & & & \\
\hline 20 & Kurangnya koordinasi antar kelompok kerja & $\sqrt{ }$ & & & $\sqrt{ }$ & & & & & & $\sqrt{ }$ & & & \\
\hline 21 & $\begin{array}{l}\text { Lokasi proyek yang jauh dari tempat tinggal } \\
\text { pekerja }\end{array}$ & $\checkmark$ & & & $\sqrt{ }$ & & & & & & & & & \\
\hline 22 & Bermalas-malasan & & $\sqrt{ }$ & & & & & & & & $\sqrt{ }$ & & & \\
\hline 23 & Kerusakan pada bangunan & & & & & & $\sqrt{ }$ & $\sqrt{ }$ & & & & & & \\
\hline 24 & Kesalah desain & & & $\sqrt{ }$ & & & & & & $\sqrt{ }$ & & & & \\
\hline 25 & Desain yang rumit & & & $\sqrt{ }$ & & & $\sqrt{ }$ & & & $\sqrt{ }$ & & & & \\
\hline 26 & $\begin{array}{l}\text { Lingkup \& Desain pekerjaan yang berubah } \\
\text { (change order) }\end{array}$ & & $\sqrt{ }$ & & & & & & & & & & $\sqrt{ }$ & \\
\hline 27 & Kurangnya kualitas pekerjaan & & $\sqrt{ }$ & & & & & & & $\sqrt{ }$ & $\sqrt{ }$ & & & \\
\hline 28 & Kurangnya komunikasi antar pekerja & & & $\sqrt{ }$ & & & & & & & $\sqrt{ }$ & & & \\
\hline 29 & $\begin{array}{l}\text { Kurangnya kontrol jadwal yang dilakukan } \\
\text { manajemen }\end{array}$ & $\checkmark$ & & & $\sqrt{ }$ & & & & & & & & & \\
\hline 30 & $\begin{array}{l}\text { Kurangnya perencanaan site (jalan susah,akses } \\
\text { untuk pekerja dan material terbatas) }\end{array}$ & $\checkmark$ & & & $\sqrt{ }$ & & & & & & & & & \\
\hline 31 & $\begin{array}{l}\text { Letak penyimpanan material dan peralatan yang } \\
\text { jauh dari area kerja }\end{array}$ & & & $\sqrt{ }$ & $\sqrt{ }$ & & & & & $\sqrt{ }$ & $\sqrt{ }$ & & & \\
\hline 32 & Prosedur permintaan material rumit & & & & $\sqrt{ }$ & & $\sqrt{ }$ & & & $\sqrt{ }$ & & & & \\
\hline 33 & $\begin{array}{l}\text { Letak tempat istirahat dan toilet yang terlalu } \\
\text { jauh dari area kerja }\end{array}$ & $\sqrt{ }$ & & & $\sqrt{ }$ & & & & $\sqrt{ }$ & & & & & \\
\hline
\end{tabular}
A. Adrian, 1987
B. Borcheding, 1976
C. Borcheding Sebastian and Samelson, 1980
D. Do, 1997
E. Chang and Ogunlana, 1998
F. Hinze, 1978
G. Hinze, Ugwu, and Hubbard, 1985
H. Kaming, Olomolaiye, Holt, and Harris 1997
I. Kaming, Olomolaiye, Holt, Kometa, and Harris 1996
J. Maloney, 1983
K. Thomas, 1992
L. Thomas and Napoltian, 1995
M. Thomas and Raynar, 1997

\subsection{Pekerjaan Finishing}

\subsubsection{Pengertian Umum}

Pekerjaan finishing adalah pekerjaan akhir dari sebuah kegiatan pembangunan dalam rangka menutupi, melapisi, dan memperindah dari sebuah bangunan atau konstruksi. Pekerjaan finishing merupakan pekerjaan yang memakan biaya cukup besar dan untuk mereduksi pekerjaan ini memang tidak mudah tetapi dapat dilakukan dengan mengurangi kesalahan dan meningkatkan kualitas serta kompetensi tenaga kerja. 


\subsubsection{Jenis dan Macam Pekerjaan Finishing}

Pekerjaan finishing dapat dibedakan menjadi 2, yaitu :

- $\quad$ Pekerjaan finishing basah adalah pekerjaan finishing yang dalam aplikasinya menggunakan air sebagai medianya yang meliputi pasangan batu bata, plesteran, acian, pasangan tegel keramik, pasangan granit, dan pekerjaan pengecatan.

- Pekerjaan finishing kering adalah pekerjaan yang dalam aplikasinya tidak menggunakan air sebagai medianya yang meliputi pekerjaan wallpaper, dinding partisi, karpet, dinding enamel, dll.

\section{METODOLOGI PENELITIAN}

\subsection{Diagram Alur Penelitian}

Secara garis besar alur penelitian yang dilakukan dapat dilihat pada Gambar 1.

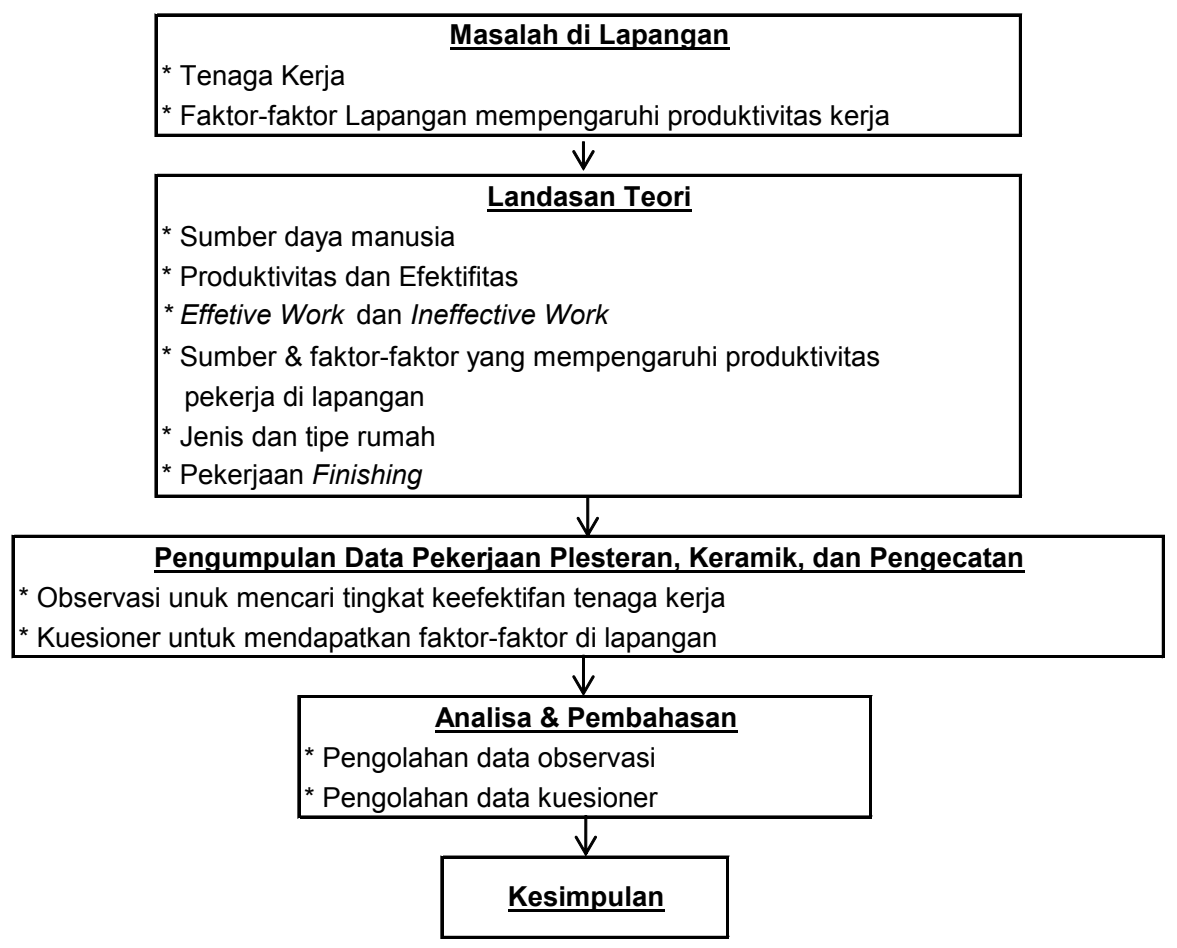

Gambar 1. Kerangka Kerja Penelitian

\subsection{Lokasi dan Waktu Penelitian}

Obyek yang akan diletiti dalam penelitian ini adalah tenaga kerja harian yang bekerja pada 10 proyek rumah tinggal di Surabaya. Jangka waktu penelitian ini antara bulan April 2016 Juli 2016.

\subsection{Teknik Pengumpulan Data}

Data dalam penelitian ini adalah data primer yang bersumber dari tenaga kerja secara langsung.Untuk memperoleh data penelitian ini digunakan dua jenis metode yaitu dengan observasi dan kuesioner.

\subsection{Observasi}

Pada bagian ini, peneliti akan mengamati efektifitas tenaga kerja pada pekerjaan finishing khususnya tukang dan pembantu tukang pada pekerjaan plesteran, keramik, dan pengecatan. Pada masing-masing proyek dilakukan dua kali pengamatan. Pengamatan dilakukan meggunakan stopwatch selama satu hari jam kerja. 


\subsubsection{Perhitungan Efektifitas Pekerjaan Finishing}

Untuk menghitung keefektifan pekerja dapat dihitung dengan cara mengelompokkan jumlah total jam orang bekerja dibagi dengan jumlah total jam pengamatan.

\subsection{Penyusunan Kuesioner}

Sebelum dilakukan penyusunan kuesioner maka ditetapkan variabel yang digunakan sebagai dasar untuk diaplikasikan dalam penelitian ini. Pada kuesioner ini, responden diminta untuk memperkirakan seberapa sering faktor - faktor lapangan yang muncul.

\section{ANALISA DAN PEMBAHASAN}

\subsection{Pendahuluan}

Dalam bab ini akan dilakukan analisa dan pembahasan tentang pengukuran efektifitas dan frekuensi faktor yang mempengaruhi produktivitas pekerja pada pekerjaan finishing proyek rumah tinggal di Surabaya. Data yang diperlukan diperoleh dari penelitian terhadap 10 proyek rumah tinggal yang berada di kota Surabaya. Pengumpulan data dilakukan dengan mengamati aktivitas pekerja pada pekerjaan plesteran, keramik, dan pengecatan. Pada pekerjaan plesteran terkumpul data sebanyak 28 pekerja, pada pekerjaan keramik terkumpul data sebanyak 21 pekerja, dan pada pekerjaan pengecatan terkumpul data sebanyak 23 pekerja. Dari data-data tersebut dapat dihitung prosentase yang menunjukkan nilai efektifitas dari masing-masing pekerja.

Data tentang pribadi dan untuk mengetahui frekuensi faktor-faktor lapangan (1) Metode dan Teknogi, (2) Manajemen Lapangan, (3) Lingkungan Kerja, (4) Manusia yang mempengaruhi produktivitas pekerja pada pekerjaan finishing diperoleh dengan penyebaran kuesioner.

\subsection{Pengolahan Data Hasil Observasi}

\subsubsection{Hasil Pengamatan Aktivitas Pekerjaan Finishing}

Waktu aktvitas tenaga kerja digolongkan kedalam 2 jenis aktivitas, yaitu bekerja (working) dan tidak bekerja (non-working). Pada masing-masing pekerjaan finishing dilakukan pencatatan selama 2 hari kerja. Jam pengamatan dicatat setiap 60 menit dan hasilnya dimasukkan kedalam lembar pengamatan.

\subsubsection{Perbandingan Aktivitas pada Pekerjaan Finishing}

Setelah dilakukan pencatatan aktivitas tenaga kerja pada pekerjaan finishing, dihitung nilai keefektifan pekerja yang terdapat dalam 10 proyek rumah tinggal di Surabaya. Hasil rekapitulasi menunjukkan bahwa prosentase efektif tukang pada pekerjaan plesteran sebesar 83,86 \%. Prosentase efektif tukang pada pekerjaan keramik sebesar $86,22 \%$. Prosentase efektif tukang pada pekerjaan pengecatan sebesar $82,88 \%$. Sedangkan prosentase efektif pembantu tukang sebesar $80,22 \%$. Prosentase efektif pembantu tukang pada pekerjaan keramik sebesar $78,34 \%$. Prosentase efektif pembantu tukang pada pekerjaan pengecatan sebesar $79,51 \%$.

\subsection{Pengolahan Data Hasil Kuesioner \\ 4.3.1. Deskripsi Karakteristik Responden}

Karakteristik responden yang dibahas dalam penelitian ini adalah umur responden, pengalaman kerja responden, lama kerja responden, pendidikan responden, dan upah responden.

\subsubsection{Deskripsi Variabel Penelitian pada Pekerjaan Finishing}

Nilai rata-rata tertinggi pada pekerjaan plesteran sebesar 4,04 yaitu nilai pada item pernyataan ke-31 dan ke-33. Sedangkan nilai rata-rata terendah sebesar 2,86 yaitu nilai rata-rata pada item pernyataan ke-11 dan ke-19. Nilai rata-rata tertinggi pada pekerjaan keramik sebesar 4,00 yaitu nilai pada item pernyataan ke-26. Sedangkan nilai rata-rata terendah sebesar 2,81 yaitu nilai pada item pernyartaan ke-21. Nilai rata-rata tertinggi pada pekerjaan pengecatan sebesar 3,83 yaitu nilai pada item penyataan ke-4 dan ke-10. Sedangkan nilai rata-rata terendah sebesar 2,48 yaitu nilai pada item pernyataan ke-21. 


\subsubsection{Perbandingan Variabel Penelitian pada Pekerjaan Finishing}

Nilai rata-rata tertinggi variabel Metode dan Teknologi pada pekerjaan plesteran, keramik, dan pengecatan adalah lingkup \& desain pekerjaan yang berubah. Nilai rata-rata tertinggi variabel Manajemen Lapangan pada pekerjaan plesteran dan keramik adalah tidak tersedianya material. Sedangkan pada pekerjaan pengecatan adalah tidak tersedianya perlengkapan tukang. Nilai rata-rata tertinggi variabel Lingkungan Kerja pada pekerjaan plesteran, keramik, dan pengecatan adalah kecelakaan kerja. Nilai rata-rata tertinggi variabel Manusia pada pekerjaan plesteran adalah bermalas-malasan dan keletihan. Pada pekerjaan keramik adalah rendahnya kemampuan pekerja, keletihan, dan bermalasmalasan. Pada pekerjaan pengecatan adalah rendahnya kemampuan pekerja.

\section{KESIMPULAN DAN SARAN}

\subsection{Kesimpulan}

Dari hasil pengamatan dan penyebaran kuesioner pada pekerjaan finishing proyek rumah tinggal di Surabayadidapatkan beberapa kesimpulan:.

1. Rata-rata nilai keefektifan tukang tertinggi berada pada pekerjaan keramik sebesar $86,22 \%$ dan nilai keefektifan tukang terendah berada pada pekerjaan pengecatan. Nilai keefektifan tukang pada pekerjaan plesteran $83,86 \%$. Sedangkan nilai keefektifan pembantu tukang tertinggi berada pada pekerjaan plesteran sebesar $80,22 \%$ dan nilai keefektifan pembantu tukang terendah berada pada pekerjaan keramik sebesar 78,34 $\%$. Nilai keefektifan pembantu tukang pada pekerjaan pengecatan sebesar $79,51 \%$. Hal ini berarti tingkat keefektifan tukang dan pembantu tukang pada masing-masing pekerjaan finishing tergolong memuaskan karena diatas $60 \%$.

2. Frekuensi faktor-faktor yang mempengaruhi produktivitas pekerja pada pekerjaan finishing dengan nilai mean paling besar hingga terkecil adalah (1) Manusia, (2) Manajemen Lapangan, (3) Lingkungan Kerja, (4) Metode dan Teknologi.

3. Kesepuluhfaktor pada pekerjaan plesteran adalah keletihan, bermalas-malasan, rendahnya kemampuan pekerja, tidak tersedianya material, kecelakaan kerja, gangguan pada saat melakukan pekerjaaan, tidak tersedianya peralatan, tidak tersedianya perlengkapan tukang, peralatan yang dipakai sudah usang/sering rusak, lingkup \& desain pekerjaan yang berubah.

4. Kesepuluh faktor pada pekerjaan keramik adalah kecelakaan kerja, tidak tersedianya material gangguan pada saat melakukan pekerjaan, peralatan yang dipakai sudah usang/sering rusak, tidak tersedianya peralatan, kurangnya instruksi dari mandor, lingkup \& desain pekerjaan yang berubah, rendahnya kemampuan pekerja, keletihan,bermalas-malasan.

5. Kesepuluh faktor pada pekerjaan pengecatan adalah lingkup \& desain pekerjaan yang berubah, tidak tersedianya perlengkapan tukang, tidak tersedianya peralatan, kecelakaan kerja, kerusakan pada bangunan, kurangnya instruksi dari mandor, kondisi kerja yang tidak aman, rendahnya kemampuan kerja, keletihan, bermalas-malasan.

\subsection{Saran}

Beberapa saran yang dapat diberikan untuk penelitian selanjutnya adalah :

1. Dalam merumuskan kuesioner, sebaiknya pernyataan harus diujikan terlebih dahulu kepada responden awal untuk mengetahui apakah pernyataan tersebut dapat dijadikan instrumen penelitian.

2. Dalam melakukan pengamatan sebaiknya satu pengamat mengawasi maksimal 3 orang pada wilayah yang sama.

3. Hasil pengukuran efektifitas tenaga kerja pada penelitian ini dipengaruhi oleh karakteristik obyek penelitiannya, yaitu pekerjaan finishing pada proyek rumah tinggal. Oleh karena itu obyek penelitian selanjutnya diharapkan menggunakan jenis proyek lebih besar yang memiliki perbedaan karakteristik sehingga dapat diketahui perbedaan dan persamaan dari hasil analisanya. 
4. Kontraktor proyek rumah tinggal perlu memberikan pengawas di lapangan agar tenaga kerja dapat bekerja dengan lebih maksimal.

\section{DAFTAR REFERENSI}

Adrian, J. J. (1987). Construction Productivity Improvement. Elsivier. New York.

Borcheding, J. D. (1976). "Improving Productivity in Industrial Construction." Journal of the Construction Division, ASCE. Vol. 102, No. 4, 599-614.

Borcheding, J. D., Seastian, S. J., and Samelson, N. M. (1980). "Improving Motivation andProductivity on Large Projects." Journal of the Construction Divison, ASCE. Vol. 106,No. 1, 73-89.

Chang, W. P \& Ogunlans, S.O. (1998). "Worker Motivation on Selected Construction Sites in Bangkok, Thailand." Joumal of Engineering, Construction and Architectural Managemen. Vol. 5 , No. 1, 68-81.

Do, T. X. L. (1997). Assessment of Productivity Perception and Factors for Vietnamese Construction Personnel. (Thesis No. ST-97-35). Unpublished master thesis, Asian Institute of Technology, Bangkok.

Ervianto, W. I. (2004). Manajemen Proyek Konstruksi. Andi. Yogyakarta.

Hinze, J. (1978). "Turnover, New Workers, and Safety." Journal of the Construction Division, ASCE. Vol. 104, No. 4, 409-417.

Hinze, J., Ugwu, M., and Hubbard, L. (1985). "Absenteeism in Construction Industry." Journal of Management in Engineering, ASCE. Vol. 1, No. 4, 188-200.

Kaming, P. F., Olomaiye, P. O., Holt, G. D., Kometa, S. T. And Harris, F. C. (1996). "Project Managers Perception of Production Problems an Indonesian Case Study." Building Research and Information.Vol. 24, No. 5, 301-309.

Kaming, P. F., Olomaiye, P. O., Holt, G. D., and Harris, F. C. (1997). "Factors Influencing Craftmen's Productivity in Indonesia." International Journal of Project Management. Vol. 15, No.1, 21-30.

Maloney, W. F. (1983). "Productivity Improvement: the Influence of Labor." Joumal of Construction Engineering and Management, ASCE. Vol. 109, No. 3, 321-334.

Oglesby, C. H., Parker, H. W., and Howell, G. A. (1989). Productivity Improvement in Construction. McGraw-Hill Book Company. New York.

Olomolaiye, P., Jayawardene, A., and Harris, F. (1998). Construction Productivity Management. Chartered Institute of Building. United Kingdom.

Soeharto, I. (1995). Manajemen Proyek dari Konseptual Sampai Operasional. Erlangga. Jakarta.

Thomas, H. R. (1992). "Effects of Scheduled Overtime on Labor Productivity." Journal of Construction Engineering and Management, ASCE.Vol. 118, No. 1, 60-76.

Thomas, H. R. \& Napolitan, C. L. (1995). "Quantitive Effects of Construction Changes on Labor Productivity." Joumal of Construction Engineering and Management, ASCE. Vol. 121, No. 3, 290-296.

Thomas, H. R. \& Raynar K. A. (1997). "Scheduled Overtime and Labor Productivity Quantitive Analysis." Journal of Construction Engineering and Management, ASCE. Vol. 123, No. 2, 181-188. 